\title{
Remediation of Endosulfan by Biotic and Abiotic Methods
}

\author{
Puthenveedu Sadasivan Pillai Harikumar ${ }^{1}$, Kottekottil Jesitha ${ }^{1}$, Mannodi Sreechithra ${ }^{2}$ \\ ${ }^{1}$ Centre for Water Resources Development and Management, Kozhikode, India; ${ }^{2}$ Department of Chemical Engineering, Government \\ Engineering College, Kozhikode, India. \\ Email: hps@cwrdm.org
}

Received March 1 ${ }^{\text {st }}, 2013$; revised April 1 ${ }^{\text {st }}, 2013$; accepted April 30 ${ }^{\text {th }}, 2013$

Copyright (C) 2013 Puthenveedu Sadasivan Pillai Harikumar et al. This is an open access article distributed under the Creative Commons Attribution License, which permits unrestricted use, distribution, and reproduction in any medium, provided the original work is properly cited.

\begin{abstract}
Endosulfan is a persistent, toxic broad-spectrum organochlorine insecticide and acaricide used on food and non-food crops. To overcome the problem of hydrophobicity of endosulfan, surfactants play a major role in soil remediation. A concentration of $1 \mathrm{~g} / \mathrm{L}$ tween 80 released $83.89 \pm 1.22 \%$ of endosulfan from the soil in 24 hours and a total of only $13.96 \pm 0.14 \%$ was found remaining in the soil. Phytoremediation is an emerging technology that promises effective and inexpensive cleanup of contaminated hazardous waste sites. The potential of aquatic plant species Salvinia molesta and the terrestrial plant species, Spinach (Spinacia oleracea) and Tomato (Solanum lycopersicum), to remove persistent organochlorine pesticide endosulfan from contaminated water and soil respectively were investigated. Remediation of endosulfan in water using different aquatic plants showed that Salvinia molesta is more efficient in endosulfan removal as the percentage removal of endosulfan obtained was $97.94 \pm 0.33 \%$ in 21 days (with an initial concentration of 123 $\mu \mathrm{g} / \mathrm{L}$ endosulfan). Among the selected terrestrial plant species, Spinach and Tomato, percentage removal of endosulfan was found to be higher with Tomato. On Day 21, complete removal of pesticide (with an initial concentration of $140 \mu \mathrm{g} / \mathrm{Kg}$ endosulfan) occurred in the soil in which phytoremediation was done with Tomato while Spinach took about 28 days for complete removal of endosulfan. Microbial degradation offers an effective approach to remove toxicants from the environment. Microbial degradation of endosulfan was studied and Pseudomonas species was able to completely degrade endosulfan in 16 days. The technologies developed can be utilized for the complete removal of endosulfan from a contaminated area. The surfactant enhanced recovery and phytoremediation will help to decontaminate the polluted water and soil. The recovered endosulfan in the surfactants and plants can be subjected to biodegradation by bacterial species using a bio reactor.
\end{abstract}

Keywords: Endosulfan; Surfactant; Tween 80; Phytoremediation; Pseudomonas

\section{Introduction}

Endosulfan is a persistent organic pollutant that enters the air, water and soil during its use and manufacture. Introduced in the 1950's, it emerged as a leading chemical used against a broad spectrum of insects and mites in agriculture and allied sectors. Endosulfan and its break down products are persistent in the environment with an estimated half-life of 9 months to 6 years. Endosulfan generally has been shown to have high acute oral and inhalation toxicity as well as slightly toxic dermal toxicity. Endosulfan primarily affects the nervous system. Toxic effects observed in animals from acute, subchronic, developmental neurotoxicity, and chronic carcinogenic toxicity studies found that endosulfan causes neurotoxic effects, which are believed to result from over-stimulation of the central nervous system [1].
The unscientific use of pesticides and other agrochemicals result in the pollution of many water bodies. Because of the reported cases of endosulfan problem and related health issues, in Kasargod district, a total of 63 samples including water, soil and sediment samples from eleven selected panchayaths of Kasargod district were analyzed to study the persistence of endosulfan. The level of the toxic pesticide, endosulfan in all the analyzed samples were within the World Health Organization guideline limits and the recovery of endosulfan from the soil and sediment samples reported maximum values of $16.91 \mu \mathrm{g} / \mathrm{Kg}$ and $6.22 \mu \mathrm{g} / \mathrm{Kg}$ respectively [2]. Although the level of organochlorine pesticides in many water sources were slightly lower than the limit prescribed by International regulatory agency, such low doses consumed for longer durations may act as endocrine dis- 
rupting agents and cause metabolic disorders. The study on the persistence of endosulfan in selected Panchayaths of Kasargod district formed the basis of the study of different remedial methods to remove endosulfan from contaminated water and soil. The developed methods can be beneficial to the society and was found to be cost effective and environment friendly.

Degradation of endosulfan and other chlorinated pesticides can be achieved through different biotic and abiotic techniques [3]. These include microbiological or chemical processes. Chemical degradation occurs by photolysis, oxidation and reduction reactions while biological degradation occurs through the action of environmental microorganisms. The extensive presence of pesticides in the water and soil has stimulated interest in finding solutions for the treatment or removal of residues from the environment.

The natural degradation of pesticides consumes time, so the processes that accelerate the decontamination of the affected environment are significant. To overcome the problem of hydrophobicity, surfactants play a major role in soil remediation. Surfactants are amphiphilic compounds which can reduce surface and interfacial tensions by accumulating at the interface of immiscible fluids and increase the solubility, mobility, bioavailability and subsequent biodegradation of hydrophobic or insoluble organic compounds. Addition of a surfactant of chemical or biological origin accelerates or sometimes inhibits the bioremediation of pollutants. Surfactants increase the concentration of a hydrophobic compound in the aqueous phase by emulsification and solubilization [4].

Phytoremediation is an emerging technology that promises effective and inexpensive cleanup of contaminated hazardous waste sites [5]. Plants can interact with hazardous organic compounds through degradation or accumulation [6]. Phytoremediation is an environmentally sound technology for pollution prevention, control and remediation. There are several ways that plants can be used for the phytoremediation of the contaminants like phytodegradation, rhizodegradation, and phytovolatilisation. Phytoextraction, also called phytoaccumulation, refers to the uptake of contaminants from soil by plant roots into above-ground portions of plants. Phytoremediation has been used to clean up metals, pesticides, solvents, explosives, crude oil, polyaromatic hydrocarbons, and landfill leachates. Phytoremediation is the direct use of living green plants for in situ, or in place, risk reduction for contaminated soil, sludges, sediments, and groundwater, through contaminant removal, degradation, or containment. Growing and, in some cases, harvesting plants on a contaminated site as a remediation method is an aesthetically pleasing, solar-energy driven, passive technique that can be used to clean up sites with shallow, low to moderate levels of contamination [7].

Microbial degradation offers an effective approach to remove toxicants from the environment. Microorganisms play an important role in the conversion of cyclodiene insecticides in soil to nontoxic products. In the natural environment microorganisms provide some protection against toxicity of endosulfan. The ultimate economically viable and environmentally friendly solution for the pollution abatement of chemicals that are thought to be recalcitrant or non-biodegradable, is the application of environmental biotechnology i.e., bioremediation using selected microbes [8].

This study reports the remediation of endosulfan from contaminated water and soil using biological and chemical methods.

\section{Materials and Methods}

\subsection{Reagents and Standards}

Technical grade endosulfan $(\alpha+\beta$-endosulfan $)$ and endosulfan sulphate of $98.5 \%$ purity was obtained from $\mathrm{E}$. Merck (Germany) to compare and quantify the sample concentrations. All the reagents used were of analytical grade.

\subsection{Chemical Enhanced Recovery of Endosulfan}

In the chemical method, batch sorption runs for different endosulfan concentrations were carried out by agitating soil with $1 \mathrm{~g} / \mathrm{L}$ of Tween 80, Triton X 100 and Mannitol in stoppered bottles on a mechanical shaker. At the end of predetermined time intervals, the supernatant was extracted and analyzed for endosulfan.

The soil, collected from the experimental plot of Centre for Water Resources Development and Management, Kozhikode, was sterilized by autoclaving $\left(121^{\circ} \mathrm{C}\right.$ at 15 psi) for $1 \mathrm{~h}$ before. After autoclaving, the soil was incubated on nutrient agar medium at $36^{\circ} \mathrm{C}$ for $48 \mathrm{~h}$ and no microbial growth was observed. Weighed $10 \mathrm{~g}$ of sieved soil sample in an electronic weighing balance to a $250 \mathrm{ml}$ Erlenmeyer flask. The soil was artificially contaminated with $100 \mu \mathrm{g} / \mathrm{Kg}$ endosulfan. The contaminated soil was mixed with $20 \mathrm{ml}$ of different selected surfactant solutions (Tween 80, Triton X 100 and Mannitol of 1 $\mathrm{g} / \mathrm{L})$. Control experiments without the surfactant solutions were also maintained. The samples were equilibrated on a rotary shaker for $3 \mathrm{hrs}$ at $38^{\circ} \mathrm{C}$. Three replicates were maintained for each concentration. The samples were collected at 1, 2 and 3 hours. Tween 80 enhanced recovery of endosulfan was recorded for 24 hours. An aliquot of $10 \mathrm{~mL}$ of each supernatant was transferred to a separating funnel for liquid-liquid extraction with hexane. The hexane layer was separated and used for further analysis. The confirmation of the recovery was 
done by extracting the remaining soil after the supernatant analysis.

\subsection{Phytoremediation Using Selected Plant Species}

The effectiveness of commonly available aquatic plant species such as Salvinia molesta, Hydrilla verticillata and Salvinia minima to remediate endosulfan contaminated water was investigated. Also the terrestrial plant species such as Spinach (Spinacia oleracea) and Tomato (Solanum lycopersicum) were transplanted into soil and artificially spiked with endosulfan. Water and soil samples were analyzed at different intervals to find out the total recoverable endosulfan.

The effectiveness of free floating aquatic plant species such as Giant salvinia (Salvinia molesta) and Water spangles (Salvinia minima) and also submerged aquatic species Hydrilla (Hydrilla verticillata) to remediate endosulfan contaminated water was investigated. The phytoremediation by Salvinia molesta in water was carried out using water sample artificially spiked with $123 \mu \mathrm{g} / \mathrm{L}$ endosulfan and a portion of the spiked samples were removed at different intervals $(0,3,7,14,21$ and 28 days) and analyzed for total recoverable endosulfan.

Two terrestrial plant species, Spinach (Spinacia oleracea) and Tomato (Solanum lycopersicum) were selected for the investigation of the pesticide removal from soil. Triplicate plant chambers were used for Spinacia oleracea whereas quadruplicate chambers were used for Solanum lycopersicum Medium growing plants with extensive rooting system were selected for the study. Half month old seedlings were transplanted into rectangular shaped growth chambers, which were then placed in a controlled-temperature greenhouse. Water was added daily to adjust the soil to appropriate moisture content. Natural light was used for the green house study. Soil required for the study was collected from the experimental plot of Centre for Water Resources Development and Management (CWRDM), Kozhikode. The soil samples were collected from the experimental plot and subjected to chemical analysis as per standard methods $[9,10]$. The soil selected for the study was sampled and characterized. An amount of $3.5 \mathrm{~kg}$ of soil taken in each experimental tray was spiked with about $140 \mu \mathrm{g} / \mathrm{Kg}$ of endosulfan and the selected terrestrial plants were grown in the phytoremediation areas. Control experiments without the plant species were also laid to study natural degradation of the pesticide. The soil samples were collected from the experimental site at regular intervals and analyzed for endosulfan after $0,7,14,21$ and 28 days.

The aquatic and terrestrial plants used for remediation were also extracted and the concentration of endosulfan was determined. All the samples were extracted and processed separately following standard methods [11,12]. Isomers of endosulfan (endosulfan-alpha, endosulfan-beta) and endosulfan sulphate were determined during the analysis of the samples.

\section{Extraction of Pesticide Residues}

For the extraction of the pesticide residues from water, liquid-liquid extraction method was adopted. Extraction of pesticides from soil required a more polar solvent than hexane or dichloromethane alone. Hence a mixed extracting solvent with added acetone was used. Organics were extracted by shaking with a solvent mixture of chromatographic grade n-hexane and acetone. Extraction of pesticide residues were carried out following standard methods with some modifications. For extraction of water samples, one litre water sample was taken into a separating funnel. It was mixed with $30 \mathrm{~g}$ of $\mathrm{NaCl}$ and 50 $\mathrm{ml}$ of $\mathrm{n}$-hexane. Sample was shaken well and hexane layer was separated. This process was repeated thrice and hexane portions were pooled together. The co extractives were removed from the concentrated extract on an alumina column overlaid with $1 \mathrm{~g}$ anhydrous sodium sulphate to remove any remaining water molecules. The extract was concentrated to around $10 \mathrm{ml}$ on rotary evaporator. The concentrated extract was transferred to airtight, amber coloured $\mathrm{GC}$ vials and stored at $4^{\circ} \mathrm{C}$ until analysis $[11,12]$

For the extraction of pesticide residues from plants, samples were placed in glass tubes, homogenized twice with $4 \mathrm{ml}$ of ethyl acetate. An additional solvent $(2 \mathrm{ml})$ was utilized each time for washing. The homogenized samples were centrifuged for $10 \mathrm{~min}$ at $4600 \mathrm{rev} . / \mathrm{min}$, the extract was transferred to another tube and concentrated to $1 \mathrm{ml}$. Clean-up was accomplished by passing the extract through a column containing a small amount of glass wool at the base and $3.5 \mathrm{~g}$ of aluminium oxide with a thin layer of anhydrous sodium sulfate lying on top. A hexane-ethyl acetate $(80: 20, \mathrm{v} / \mathrm{v})$ mixture $(10 \mathrm{ml})$ was used to elute the pesticides from the column. Finally, the extracts were concentrated to an appropriate volume (2 $10 \mathrm{ml}$ ) and analyzed by GC-ECD [13].

\subsection{Bioremediation of Endosulfan}

In the bioremediation study, endosulfan degrading bacterial species was isolated from the soil collected from cashew plantation of Kasargode district, Kerala. The two isolates, Pseudomonas and Bacillus species were utilized to remediate different concentrations of endosulfan (77 $\mu \mathrm{g} / \mathrm{L}$ and $119 \mu \mathrm{g} / \mathrm{L})$. Uninoculated culture was maintained as control in order to compare the difference in degradation of endosulfan. Surface soil $(0-10 \mathrm{~cm})$ was removed using a spade and placed in plastic bags. The soil was transported to laboratory, sealed in biological 
bottles and stored at $4{ }^{\circ} \mathrm{C}$ until use.

\subsubsection{Isolation of Endosulfan Degrading Soil Bacteria}

$1 \mathrm{~g}$ of fresh soil sample was added to sterile distilled water. Serial dilution method was used for isolation of bacteria using Soil Extract Medium and incubated at room temperature $\left(29^{\circ} \mathrm{C}\right)$. Six strains were isolated. Among the isolated cultures two were sub cultured as both showed different morphological characters. By repeated sub culturing, pure cultures were obtained. Strains were maintained on nutrient agar slants.

Gram staining was used for studying the morphological characters of the isolates. Depending upon the Grams reaction, the organisms were identified as Gram positive or Gram negative. Depending upon the shape, the organism was identified as cocci or bacilli.

\subsubsection{Extraction of Endosulfan from Different Samples}

$5 \mathrm{ml}$ of the sample was homogenized by adding 3 to 5 drops of concentrated $\mathrm{HCl}$. The homogenised sample was extracted by thoroughly vortexing with $5 \mathrm{ml}$ of Hexane: acetone (80:20) and centrifuged at $2000 \mathrm{rpm}$ for 25 $\min$. The organic layer that separated was dried over anhydrous sodium sulphate prior to injection for gas chromatographic analysis. Degradation of endosulfan by bacterial species was determined by monitoring endosulfan disappearance by gas chromatography with electron capture detection.

\subsection{Analysis of Pesticide Residues}

After processing the samples through the different extraction steps, the final concentrated and cleaned up sample was analyzed using Gas Chromatograph using Electron Capture Detector which is specific and highly sensitive for halogenated compounds. A Varian make CP3800 Gas Chromatograph equipped with $\mathrm{Ni}^{63}$ ECD electron capture detector was used to analyze the pesticides. One microlitre volume of each extract was injected into the injection port using the micro syringe.

WCOT fused silica capillary column of length $30 \mathrm{~m}$, $0.32 \mathrm{~mm}$ internal diameter, $0.25 \mu \mathrm{m}$ film thickness was fitted and standard temperature programs were used. Nitrogen $(99.999 \%$ purity) was used as the carrier gas and the gas inlet pressure was 80 psi corresponding to a flow rate of $2 \mathrm{ml} \cdot \mathrm{min}^{-1}$. The temperature for injector and detector were $250^{\circ} \mathrm{C}$ and $300^{\circ} \mathrm{C}$, respectively. The temperature column was programmed from 130 (hold $1 \mathrm{~min}$ ) to $200^{\circ} \mathrm{C}$ at $5^{\circ} \mathrm{C}$ (hold $10 \mathrm{~min}$ ) and then from $200^{\circ} \mathrm{C}$ to $232^{\circ} \mathrm{C}$ at $1^{\circ} \mathrm{C} \min ^{-1}$ [14]. The chromatograms were recorded and integrated using Star Workstation software. The pescides detected were compared with that of the standards.
Accuracy within-day and between-day precision were assessed using QC samples at three concentration levels of 50,100 and $200 \mu \mathrm{g} / \mathrm{L}$. The samples were all run in triplicate $(n=3)$ on three different days and the RSD and relative error (RE) were calculated for each. Acceptable precision here was considered to be an RSD of $<5 \%$. The overall accuracy was assessed by subtracting the theoretical concentration of each QC sample from the mean concentration determined from the three days of analyses. detection (LOD) and quantitation (LOQ) limits were calculated relative to the values for the blank at the retention times of the analytes (10 injections).

\section{Results and Conclusions}

\subsection{Chemical Enhanced Recovery of Endosulfan}

In the chemical enhanced recovery study, Tween 80 was found to be most effective when compared with Triton $\mathrm{X}-100$ and Mannitol to remove the adsorbed endosulfan from soil. The endosulfan remediating efficiencies of the chemicals at different time intervals $(1,2,3$ hours) is compared in Figure 1.

The three chemicals, at different concentrations increased the extent of the release of endosulfan as compared to the control without the chemical solutions. Tween 80 helped to recover $42.55 \pm 0.19 \%$ endosulfan from contaminated soil for a time interval of three hours, where as Triton X 100 and Mannitol recovered only $20.79 \pm 0.23 \%$ and $15.44 \pm 0.09 \%$ respectively.

Percentage recovery of endosulfan from contaminated soil using Tween 80 at different time intervals is indicated in Figure 2.

A concentration of $1 \mathrm{~g} / \mathrm{L}$ Tween 80 released $83.89 \pm$ $1.22 \%$ of endosulfan from the soil in 24 hours and a total of only $13.96 \pm 0.14 \%$ was found remaining in the soil. During the first three hours high amount of recovery was observed and then the recovery was very slow. During the $12^{\text {th }}$ hour to $15^{\text {th }}$ hour there was a sudden increase in the recovery of endosulfan. A concentration of $1 \mathrm{~g} / \mathrm{L}$ Tween 80 released $83 \pm 0.97 \%$ of endosulfan from the soil in 15 hrs. Once the interfacial tension of the water and soil organic matter is reduced, the surfactant can penetrate deeper into the hydrophobic regions of the soil organic matter. That may be the reason for the sudden increase in the percentage recovery from $12^{\text {th }}$ hour to $15^{\text {th }}$ hour. The study was continued for 24 hours and the maximum percentage recovery of $83.89 \pm 1.22 \%$ was obtained.

The release of the hydrophobic compound endosulfan may be enhanced by the presence of aqueous concentration of the surfactant. Surfactants greatly increase the water solubility of organic contaminants due to the increased number of micelles $[4,15]$. The study proved that surfactant use in pesticide removal is less time consuming compared with other methods 


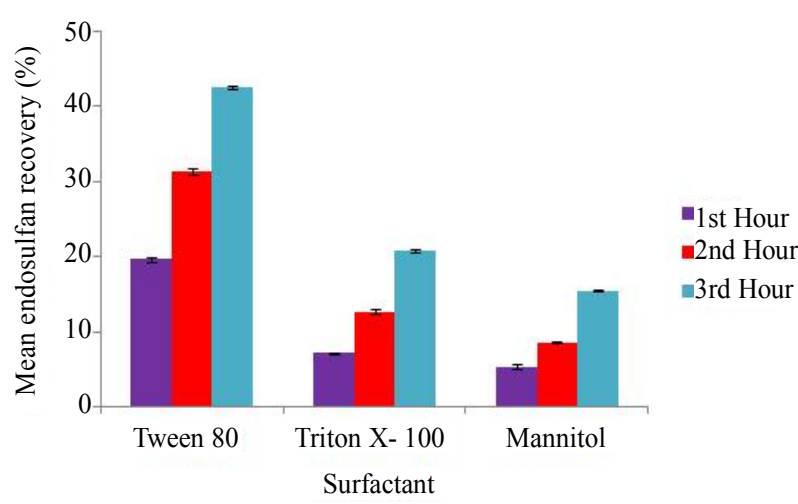

Figure 1. Comparison of percentage recovery of endosulfan using Tween 80, Triton X-100 and Mannitol at different time intervals (1, 2, 3 hrs).

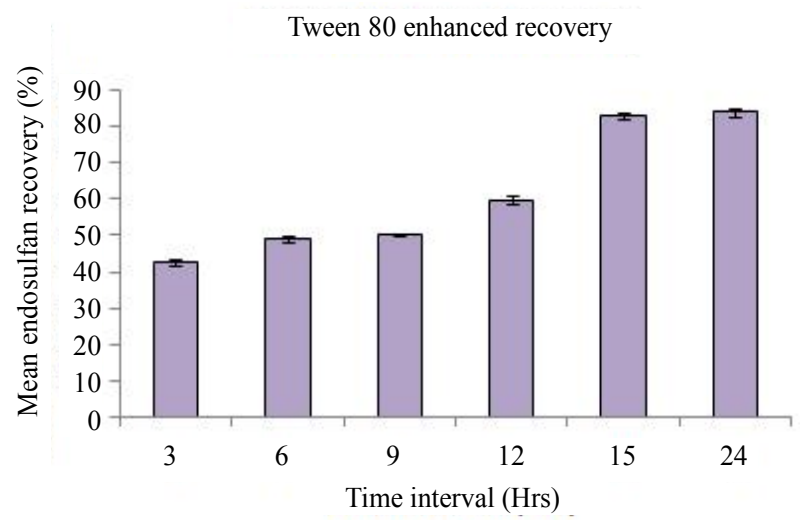

Figure 2. Mean percentage recovery of endosulfan from contaminated soil using Tween 80 at different time intervals.

of remediation.

\subsection{Phytoremediation Using Selected Plant Species}

Remediation of endosulfan in water using different aquatic plants showed that Salvinia molesta is more efficient in endosulfan removal as the percentage removal of endosulfan obtained was $97.94 \pm 0.33 \%$ in 21 days (Figure 3).

Endosulfan disappeared from soil on remediation with Salvinia molesta on day 28, while $25.86 \pm 1.1 \%$ still remained in unplanted control. Percentage removal of endosulfan by Salvinia molesta in comparison with control is indicated in Figure 4.

Confirmation of the experiment was done by the extraction of plant residue for endosulfan and found to be having a concentration of $82.22 \mu \mathrm{g} / \mathrm{Kg}$ in the aquatic plant.

In the study of endosulfan removal with selected terrestrial plant species, the percentage removal was found to be higher with tomato. The results of the study using Spinacia oleracea and the mean percentage removal of

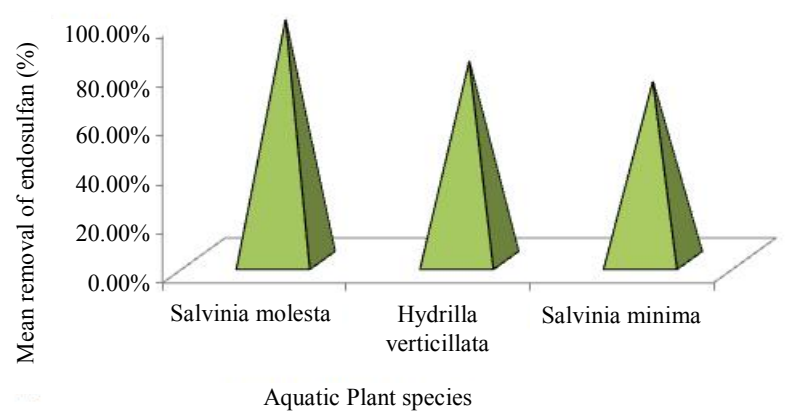

Figure 3. Comparison of endosulfan removal efficiencies of different aquatic plant species.

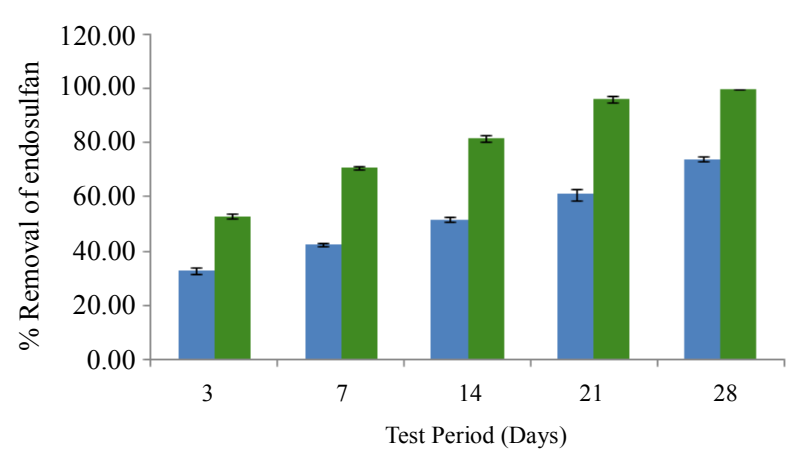

Figure 4. Percentage removal of endosulfan by Salvinia molesta in comparison with control.

endosulfan are indicated in Tables 1 and 2 respectively. Similarly the results of study and the mean percentage removal of endosulfan on phytoremediation using Solanum lycopersicum are indicated in Tables 3-5 respectively. The comparison of decrease in concentration of endosulfan by natural process and on phytoremediation is indicated in Figure 5.

On Day 21, complete removal of pesticide, occurred in the soil in which phytoremediation was done with Tomato while Spinach took about 28 days for complete pesticide removal. Extraction of plant parts residues of both terrestrial plants proved that more endosulfan re mained in the leaves. Comparison of percentage removal of endosulfan by Spinacia oleracea and Solanum lycopersicum with control is shown in Figure 6.

Endosulfan removal study using terrestrial plants have shown that the toxic metabolite endosulfan sulfate residue is detected in plant tissue along with endosulfan alpha and endosulfan beta, through the process of phytoextraction, after exposure to endosulfan. In the study of endosulfan removal with selected terrestrial plant species, Spinach (Spinacia oleracea) and Tomato (Solanum lycopersicum), the percentage removal was found to be higher with Tomato. There was no visible morphological change in plants during the treatments, which indicated that the plants could grow well in contaminated soil containing endosulfan and can help to decontaminate soil 
Table 1. Results of phytoremediation study using Spinacia oleracea.

\begin{tabular}{|c|c|c|c|c|c|c|c|c|c|c|c|c|c|c|c|}
\hline \multirow[b]{2}{*}{ Days } & \multicolumn{5}{|c|}{ Spinach 1} & \multicolumn{5}{|c|}{ Spinach 2} & \multicolumn{5}{|c|}{ Spinach 3} \\
\hline & 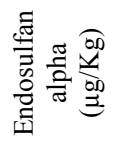 & 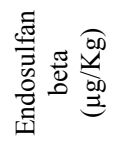 & 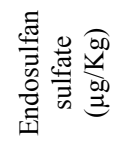 & 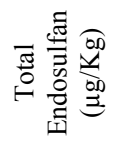 & ㅇ & 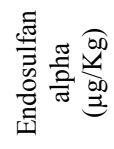 & 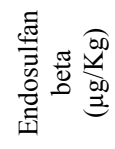 & 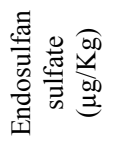 & 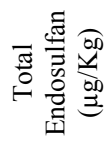 & 유 & 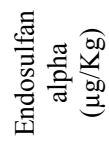 & 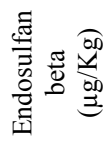 & 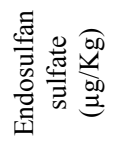 & 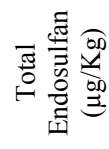 & $\therefore \stackrel{\frac{\pi}{0}}{a}$ \\
\hline 7 & 40.04 & 25.16 & 7.40 & 72.60 & 48.12 & 42.30 & 30.46 & 1.04 & 73.80 & 47.27 & 29.82 & 30.50 & 11.38 & 71.70 & 48.77 \\
\hline 14 & 21.47 & 19.60 & 10.83 & 51.90 & 62.92 & 19.68 & 17.18 & 7.54 & 44.40 & 68.27 & 23.35 & 20.86 & 2.79 & 47.0 & 66.42 \\
\hline 21 & 1.58 & 3.71 & BDL & 5.29 & 96.22 & 1.89 & 4.21 & BDL & 6.10 & 95.64 & 2.04 & 4.50 & BDL & 6.54 & 95.33 \\
\hline 28 & BDL & BDL & BDL & BDL & 100 & BDL & $\mathrm{BDL}$ & BDL & BDL & 100 & BDL & BDL & $\mathrm{BDL}$ & $\mathrm{BDL}$ & 100 \\
\hline
\end{tabular}

Initial concentration of endosulfan: $139.95 \pm 0.98 \mu \mathrm{g} / \mathrm{Kg}$; BDL: Below Detection Limit.

Table 2. Percentage removal of endosulfan on phytoremediation using Spinacia oleracea.

\begin{tabular}{ccc}
\hline Days & Mean total endosulfan $(\boldsymbol{\mu g} / \mathbf{K g})$ & Mean endosulfan removal (\%) \\
\hline 7 & $72.70 \pm 1.05$ & $48.05 \pm 0.75$ \\
14 & $47.77 \pm 3.81$ & $65.87 \pm 2.72$ \\
21 & $5.98 \pm 0.63$ & $95.73 \pm 0.45$ \\
28 & $\mathrm{BDL}$ & 100 \\
\hline
\end{tabular}

BDL: Below Detection Limit.

Table 3. Results of phytoremediation study using Solanum lycopersicum (Tomato 1, 2).

\begin{tabular}{|c|c|c|c|c|c|c|c|c|c|c|}
\hline \multirow[b]{2}{*}{ Days } & \multicolumn{5}{|c|}{ Tomato 1} & \multicolumn{5}{|c|}{ Tomato 2} \\
\hline & 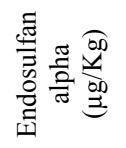 & 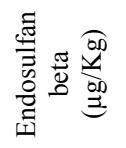 & 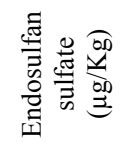 & 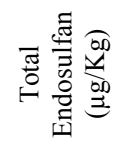 & 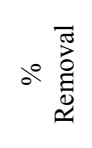 & 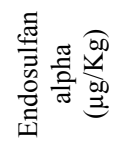 & 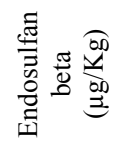 & 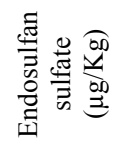 & 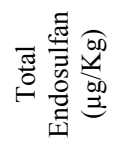 & ○。 \\
\hline 7 & 26.47 & 36.85 & BDL & 63.32 & 54.76 & 22.53 & 21.48 & 16.75 & 60.76 & 56.58 \\
\hline 14 & 4.75 & 7.18 & BDL & 11.93 & 91.48 & 4.57 & 6.01 & BDL & 10.58 & 92.44 \\
\hline 21 & $\mathrm{BDL}$ & BDL & $\mathrm{BDL}$ & BDL & 100 & BDL & BDL & BDL & BDL & 100 \\
\hline 28 & BDL & BDL & BDL & BDL & 100 & BDL & BDL & BDL & BDL & 100 \\
\hline
\end{tabular}

Initial concentration of endosulfan: $139.95 \pm 0.98 \mu \mathrm{g} / \mathrm{Kg}$; BDL: Below Detection Limit.

Table 4. Results of phytoremediation study using Solanum lycopersicum (Tomatos 3, 4).

\begin{tabular}{|c|c|c|c|c|c|c|c|c|c|c|}
\hline \multirow[b]{2}{*}{ Days } & \multicolumn{5}{|c|}{ Tomato 3} & \multicolumn{5}{|c|}{ Tomato 4} \\
\hline & 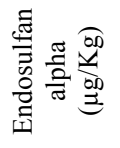 & 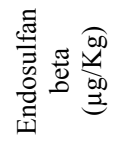 & 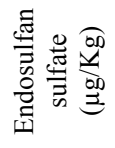 & 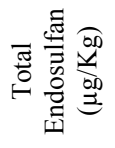 & 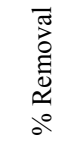 & 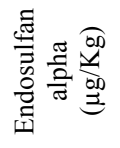 & 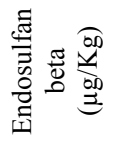 & 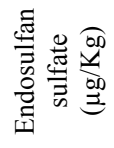 & 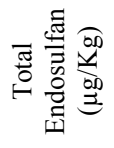 & 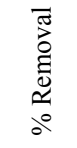 \\
\hline 7 & 16.33 & 15.70 & 25.30 & 57.33 & 59.04 & 28.25 & 28.05 & 3.20 & 59.50 & 57.48 \\
\hline 14 & 4.56 & 5.86 & BDL & 10.42 & 92.55 & 10.16 & 5.04 & BDL & 15.20 & 89.14 \\
\hline 21 & BDL & BDL & BDL & BDL & 100 & BDL & BDL & BDL & BDL & 100 \\
\hline 28 & BDL & BDL & BDL & BDL & 100 & BDL & BDL & $\mathrm{BDL}$ & BDL & 100 \\
\hline
\end{tabular}

Initial concentration of endosulfan: $139.95 \pm 0.98 \mu \mathrm{g} / \mathrm{Kg}$; BDL: Below Detection Limit. 
Table 5. Percentage removal of endosulfan on phytoremediation using Solanum lycopersicum.

\begin{tabular}{ccc}
\hline Days & Total endosulfan concentration (mean) $\mathbf{\mu g} / \mathbf{K g}$ & Mean endosulfan removal (\%) \\
\hline 7 & $60.23 \pm 2.50$ & $56.97 \pm 1.79$ \\
14 & $12.03 \pm 2.22$ & $91.40 \pm 1.58$ \\
21 & $\mathrm{BDL}$ & 100 \\
28 & $\mathrm{BDL}$ & 100 \\
\hline
\end{tabular}

BDL: Below Detection Limit.

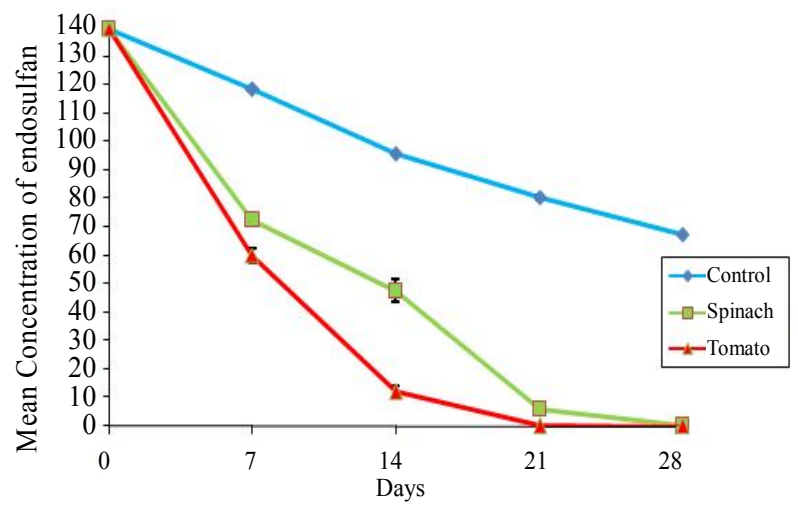

Figure 5.Concentration of endosulfan in soil in unplanted control and planted with Spinach and Tomato.

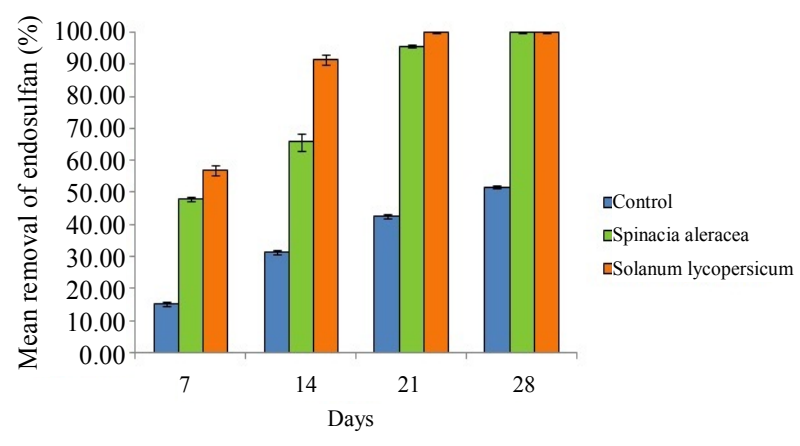

Figure 6. Comparison of percentage removal of endosulfan by Spinacia oleracea and Solanum lycopersicum with control.

and water polluted with endosulfan. Thus endosulfan removal from water and soil can be accelerated by phytoremediation, when selected plant species are used.

\subsection{Bioremediation of Endosulfan}

Microbial degradation of endosulfan was observed for 21 days. Isolation of two bacterial species was done and biochemical tests revealed that the species were Pseudomonas and Bacillus. Endosulfan isomers were extensively degraded in nutrient agar medium containing rich cultures of bacteria. Substantial degradation of both the constituents, $\alpha$ and $\beta$ was observed in 14 days with an increase in bacterial biomass. After two weeks of incuba- tion Pseudomonas species was able to degrade $98.02 \pm$ $0.18 \%$ for $119.48 \pm 0.53 \mu \mathrm{g} / \mathrm{L}$ endosulfan whereas $\mathrm{Ba}$ cillus species could degrade only $50 \pm 0.08 \%$. Uninoculated controls retained $>50 \%$ of the substrate after 14 days of incubation, indicating that only a small percentage of chemical degradation or volatilization of endosulfan had occurred. Monitoring of endosulfan residues on the 16th day revealed that complete degradation of endosulfan had occurred on bioremediation using Pseudomonas species, while then also the uninoculated control retained $>50 \%$ of endosulfan.

Results of study of biodegradation of endosulfan by two bacterial species after 14 days are shown in Table 6.

All the samples collected as a part of the biodegradation study were analyzed with GC-ECD and no intermediate compounds were identified. Endosulfan might have degraded via hydrolysis through different pathways with the formation of carbenium ions and ethyl carboxylates and finally converted to hydrocarbons [8]. Endosulfan was found to be completely degraded in 16 days, using Pseudomonas microbial strains. The results of the study implied that the bacterial strains could be employed for bioremediation of endosulfan polluted environment.

The results of the study pointed out that the proposed methods of degradation provided a rapid and efficient procedure for the removal of endosulfan. Isomers of endosulfan (i.e. endosulfan-alpha, endosulfan-beta) and endosulfan sulphate were determined during the analysis of the samples. Among the methods, chemical method helped in the recovery of endosulfan within a short time period. Bioremediation and phytoremediation proved to be an economical option for the soil decontamination. The technologies developed can be utilized for the complete removal of endosulfan from a contaminated area. The surfactant enhanced recovery and phytoremediation will help to decontaminate the polluted water and soil. The concentrated endosulfan in the surfactants and plants can be subjected to biodegradation by bacterial species using a bio reactor. Thus the different remediation techniques developed can support the need for a broad vision to develop and implement a plan for monitoring the persistence of endosulfan and address the health care and the right to a safe living environment of the society. 
Table 6. Percentage removal of endosulfan on bioremediation by isolated bacterial species.

\begin{tabular}{cccc}
\hline Bacterial species & Initial concentration of endosulfan $(\boldsymbol{\mu g} / \mathbf{L})$ & Final concentration of endosulfan $(\boldsymbol{\mu g} / \mathbf{L})$ & Removal of endosulfan $(\%)$ \\
\hline Pseudomonas & $119.48 \pm 0.53$ & $2.37 \pm 0.21$ & $98.02 \pm 0.18$ \\
Pseudomonas & $77.12 \pm 0.49$ & $16.41 \pm 0.09$ & $78.73 \pm 0.12$ \\
Bacillus & $119.48 \pm 0.53$ & $61.30 \pm 0.10$ & $50.0 \pm 0.08$ \\
Bacillus & $77.12 \pm 0.49$ & $33.40 \pm 0.47$ & $56.62 \pm 0.61$ \\
Control & $119.48 \pm 0.53$ & $110.87 \pm 0.07$ & $7.20 \pm 0.63$ \\
Control & $77.12 \pm 0.49$ & $69.34 \pm 0.37$ & $10.08 \pm 0.49$ \\
\hline
\end{tabular}

\section{Acknowledgements}

One of the authors K. Jesitha, gratefully acknowledge the financial support from Back to Lab Programme of Women Scientists Division of Kerala State Council for Science Technology and Environment, Thiruvananthapuram, Kerala.

\section{REFERENCES}

[1] United States Environmental Protection Agency, "Reregistration Eligibility Decision for Endosulfan," United States Environmental Protection Agency, Washington DC, 2002.

[2] Centre for Water Resources Development and Management, "Monitoring of Endosulfan Residues in Water, Soil and Sediment Samples of Kasaragod District, Kerala," Centre for Water Resources Development and Management, Kozhikode, 2011.

[3] Z. L. Cardeal, A. G. Souza and L. C. A. Amorim, "Analytical Methods for Performing Pesticide Degradation Studies in Environmental Samples," InTech Publishers, New York, 2011.

[4] R. Jayashree, N. Vasudevan and S. Chandrasekaran, "Surfactants Enhanced Recovery of Endosulfan from Contaminated Soils," International journal of Environmental Science and Technology, Vol. 3, No. 3, 2006, pp. 251259.

[5] I. Mukherjee and A. Kumar, "Phytoextraction of Endosulfan a Remediation Technique," Bulletin of Environmental Contamination and Toxicology, Vol. 88, No. 2, 2012, pp. 250-254. doi:10.1007/s00128-011-0454-1

[6] M. K. Banks, R. S. Govindaraju, A. P. Schwab, P. Kulakow and J. Finn, "Phytoremediation of Hydrocarbon Contaminated Soil," Lewis Publishers, Boca Raton, 2000.

[7] United States Environmental Protection Agency, "A Citizen's Guide to Phytoremediation," United States Envi- ronmental Protection Agency, Washington DC, 2001.

[8] S. Mathava Kumar and L. Philip, "Bioremediation of Endosulfan Contaminated Soils," National Conference on Conservation and Management of Wetland Ecosystems, Mahatma Gandhi University, Kottayam, 2012, pp. 34-47.

[9] C. A. Black, "Methods of Soil Analysis," American Society of Agronomy, Inc., Madison, 1965.

[10] P. R. Hesse, "Textbook of Soil Chemical Analysis," CBS Publishers, Delhi, 1971.

[11] American Public Health Association, "Standard Methods for the Examination of Water and Wastewater," 21st Edition, American Public Health Association, Washington DC, 2005.

[12] United States Environmental Protection Agency, "Methods for Organic Chemical Analysis of Municipal and Industrial Wastewater," National Technical Information Service, Springfield, 1984

[13] J. Castro, R. A. Perez, E. Miguel, C. Sanchez-Brunete and J. L. Tadeo, "Analysis of Endosulfan Isomers and Endosulfan Sulfate in Air and Tomato Leaves by Gas Chromatography with Electron-Capture Detection and Confirmation by Gas Chromatography-Mass Spectrometry," Journal of Chromatography A, Vol. 947, No. 1, 2002, pp. 119-127. doi:10.1016/S0021-9673(01)01598-9

[14] J. L. Martinez Vidal, M. Moreno Frias, A. Garrido Frenich, et al., "Trace Determination of a- and b-Endosulfan and Three Metabolites in Human Serum by Gas Chromatography Electron Capture Detection and Gas Chromatography Tandem Mass Spectrometry," Rapid Communications in Mass Spectrometry, Vol. 14, No. 11, 2000, pp. 939-946.

doi:10.1002/(SICI)1097-0231(20000615)14:11<939::AID -RCM969>3.0.CO;2-T

[15] M. J. Rosen, "Micelle Formation of Surfactants: In Micelle Formation by Surfactants," John Wiley and Sons, New York, 1989, pp. 108-169. 